\title{
COMPOSIÇÃO DO BANCO DE PLÂNTULAS EM ÁREA DE MANGUEZAL DA FLORESTA NACIONAL DO IBURA, SERGIPE
}

\author{
COMPOSITION OF THE SEEDLING BANK IN THE MANGUEZAL AREA OF THE IBURA NATIONAL FOREST, \\ SERGIPE \\ COMPOSICIÓN DEL BANCO DE SEMLLAS EN EL ÁREA MANGUEZAL DEL BOSQUE NACIONAL IBURA, \\ SERGIPE
}

\section{Resumo}

\author{
Francineide Bezerra Gonçalves ${ }^{1}$ \\ Robério Anastácio Ferreira² \\ Anabel Aparecida de Mello3 \\ Dráuzio Correia Gama ${ }^{4}$ \\ Thadeu Ismerim Silva Santos 5 \\ Ednei Santos de Almeida ${ }^{6}$ \\ Ana Paula do Nascimento Prata ${ }^{7}$
}

Manguezais são áreas restritas às zonas entre marés do litoral e ilhas das regiões tropicais, associados a estuários, baías e lagunas. Entretanto, por ações antrópicas e atividades sem planejamento, essas áreas têm sido degradadas, com destaque a supressão da vegetação para usos como energia e para a ocupação urbana. Este trabalho foi realizado com objetivo de conhecer a regeneração natural, por meio da composição do banco de plântulas, de uma área de Manguezal da Floresta Nacional do Ibura, em Nossa Senhora do Socorro, Sergipe. A área estudada corresponde a 7,65ha, onde foram estabelecidos seis transectos perpendiculares à margem do rio e demarcadas 13 parcelas (10m x 10m). Foram mensurados todos os indivíduos com altura de $0,30 \mathrm{~m}$ a 1,00 $\mathrm{m}$, do banco de plântulas, medindo-se também o diâmetro à altura do solo. Encontrou-se 147 plântulas durante o período de avaliações, nas parcelas avaliadas. Houve uma redução de 34\% no número de plântulas da primeira para segunda avaliação e de $63 \%$ da primeira para última. O banco de plântulas é composto por: Laguncularia racemosa (L.) C. F. Gaertn, Rhizophora mangle L. e Avicennia schaueriana Stapf \& Leechm. Ex Moldenke, porém, com predominância de Rhizophora mangle L.

1 Universidade Federal de Sergipe (UFS), franfloresta@gmail.com

2 Departamento de Ciências Florestais, Universidade Federal de Sergipe (UFS), roberioaf@yahoo.com. br

3 Departamento de Ciências Florestais, Universidade Federal de Sergipe (UFS), anabel_mello@yahoo. com.br

4 Universidade Estadual do Sudoeste da Bahia (Uesb), drauziogama@hotmail.com

5 Projeto Azahar: Flor de Laranjeiras - Fundação de Apoio à Pesquisa e Extensão de Sergipe (Fapese), thadeuismerim@yahoo.com.br

6 Universidade Federal de Sergipe (UFS), ednei_salmeida@yahoo.com.br

7 Universidade Federal de Alagoas (Ufal) apprata@yahoo.com.br 
Palavras-chave: mangue, Floresta Nacional do Ibura, Rhizophora mangle e Laguncularia racemosa.

\begin{abstract}
Mangroves are areas restricted to tidal areas along the coast and islands of tropical regions, associated with estuaries, bays and lagoons. However, due to anthropic actions and unplanned activities, these areas have been degraded, with emphasis on the suppression of vegetation for uses such as energy and for urban occupation. This work was carried with the purpose of knowing the natural regeneration, through the composition of the seedling bank, of a Mangrove area of the Ibura National Forest, in Nossa Senhora do Socorro, Sergipe. The studied area corresponds to 7.65ha, where six transects perpendicular to the river were established and 13 plots (10m x 10m) were demarcated. All individuals with a height of $0.30 \mathrm{~m}$ to $1.00 \mathrm{~m}$ were measured from the seedling bank, also measuring the diameter at the height of the soil. Seedlings were found during the evaluation period in the plots evaluated. There was a $34 \%$ reduction in the number of seedlings from the first to the second evaluation and $63 \%$ from the first to the last. The seedling bank consists of: Laguncularia racemosa (L.) C.F. Gaertn, Rhizophora mangle L. and Avicennia schaueriana Stapf \& Leechm. Ex Moldenke, however, with predominance of Rhizophora mangle L.
\end{abstract}

Keywords: mangrove, Ibura National Forest, Rhizophora mangle and Laguncularia racemose.

\title{
Resumen
}

Los manglares son áreas restringidas a áreas entre mareas costeras e islas en regiones tropicales, asociadas con estuarios, bahías y lagunas. Sin embargo, debido a acciones y actividades antrópicas sin planificación, estas áreas se han degradado, con énfasis en la supresión de la vegetación para usos como la energía y la ocupación urbana. Este trabajo se realizó con el objetivo de conocer la regeneración natural, a través de la composición del banco de plántulas, de un área de manglar en el Bosque Nacional de Ibura, en Nossa Senhora do Socorro, Sergipe. El área estudiada corresponde a 7.65ha, donde se establecieron seis transectos perpendiculares en la orilla del río y se delimitaron 13 parcelas (10m x 10m). Se midieron todos los individuos con una altura de $0,30 \mathrm{~m}$ a 1,00 $\mathrm{m}$ desde el banco de plántulas, y también se midió el diámetro a nivel del suelo. Se encontraron 147 plántulas durante el período de evaluación, en las parcelas evaluadas. Hubo una reducción del 34\% en el número de plántulas de la primera a la segunda evaluación y del 63\% de la primera a la última. El banco de plántulas comprende: Laguncularia racemosa (L.) C. F. Gaertn, Rhizophora mangle L. y Avicennia schaueriana Stapf \& Leechm. Ex Moldenke, sin embargo, con predominio de Rhizophora mangle L.

Palabras clave: manglar, bosque nacional de Ibura, Rhizophora mangle y Laguncularia racemosa. 


\section{INTRODUÇÃO}

Manguezais são áreas restritas às zonas entre marés do litoral e ilhas das regiões tropicais, associados a estuários, baías e lagunas, possuindo uma flora com capacidade elevada de adaptação a condições ambientais extremas (SANTOS et al. 2015), indispensável para a manutenção da produtividade de todo ecossistema costeiro e suas adjacências (ESPÍNDOLA e ALMEIDA, 2015). São constituídos de espécies vegetais caracterizadas por se adaptarem à elevada salinidade e de formas próprias de colonizarem sedimentos lodosos, com baixos teores de oxigênio (CASASCO et al. 2014). Em diversos países, os Manguezais são os ecossistemas costeiros mais ameaçados. Estima-se que 50\% já tenham desaparecido, com grande parte dos remanescentes ainda em risco, devido às atividades antrópicas (CASASCO et al. 2014).

De acordo com o Atlas dos Manguezais do Brasil, publicado em 2018, avaliase que $25 \%$ da área original desse ecossistema foi destruída por ações antrópicas, que ocorrem desde o começo do século 20. Atualmente, estima-se que as áreas remanescentes totalizem 1.398.96o ha, estendendo-se do Amapá até Santa Catarina (BRASIL, 2018). Ainda, segundo o relatório, a maior área de Manguezal do Nordeste (que é também a maior do Brasil), corresponde a 36\% da área total de Manguezal do país, e situa-se no Estado do Maranhão (BRASIL, 2018).

Na Região Nordeste, o nível de fragmentação é ainda mais grave, estimandose perdas contínuas em quase todos os Manguezais de suas áreas costeiras, que estão degradados em níveis variáveis e distintos, em razão das diferentes pressões antrópicas (NASCIMENTO e SASSI, 2001; CARVALHO e FONTES, 2007; RABELO et al. 2011; GUIMARÃES et al. 2012; MOURA-FÉ et al. 2014; PINHEIRO e MACHADO, 2016). Como exemplo deste processo, pode-se citar áreas de Manguezal do estuário de Capiberibe, em Pernambuco, no Nordeste, que tiveram sua vegetação reduzida em quase 50\%, que corresponde a uma redução de 725 ha para 313 ha, em 10 anos (MELO e SILVA, 2018), ainda que tentativas de recuperação tenham sido realizadas (CASASCO et al. 2014; PAULA et al. 2016).

A supressão das áreas de Manguezais, por ações antrópicas e atividades sem planejamento, ocorre principalmente para a ocupação com construções imobiliárias e para a instalação de atividades de aquicultura (criação de peixes, camarões e ostras). Isto implica na fragmentação da paisagem, o que vem a comprometer os atributos biofísicos cada vez mais intensamente (CARVALHO e FONTES, 2007; MEIRELES e CAMPOS, 2010; CASASCO et al. 2014; SILVA e SOUZA, 2014).

No Estado de Sergipe, as áreas de Manguezais equivalem a 1,9\% do total brasileiro, predominando os manguezais do tipo ribeirinho nos estuários dos rios São Francisco, Japaratuba, Sergipe, Vaza-Barris e do Piauí-Fundo-Real (BRASIL, 2018). No estuário da Bacia Hidrográfica do Rio Sergipe, situa-se a Floresta Nacional do Ibura (FLONAI), entre os municípios de Laranjeira e Nossa Senhora do Socorro (BRASIL, 2005). 
No entorno da FLONAI, a vegetação de manguezal se destaca ocupando $10,44 \%$ da área. Constitui-se num importante ecossistema no contexto da conservação ambiental e na manutenção de atributos biofísicos (SILVA et al. 2013a; 2013b). Todavia, as pressões antrópicas têm implicado em sua redução, tornando-a uma paisagem bastante fragmentada (SILVA e SOUZA, 2014). Considerando-se esse elevado grau de antropização, várias discussões têm ocorrido em torno da problemática da degradação, existindo poucas experiências relatadas a respeito da recuperação destes ambientes. Entretanto, para o entendimento dos mecanismos que promovem a sua recuperação, são imprescindíveis investigações como a dinâmica da regeneração natural e a caracterização dos fatores que influenciam, tais como, condições microclimáticas e fontes de propágulos (VASCONCELOS e NERY, 2013). Uma vez que o conhecimento de fatores como esses, conforme Nascimento et al. (2016), auxilia na definição de planejamento, conservação e recuperação ambiental.

Nesse sentido, este trabalho foi realizado com o objetivo de conhecer a composição e a estrutura do banco de plântulas de um trecho do Manguezal da Floresta Nacional do Ibura (FLONAI), situado no município de Nossa Senhora do Socorro-SE.

\section{MATERIAL E MÉTODOS}

\section{Caracterização da área de estudo}

A área de Manguezal estudada localiza-se na Floresta Nacional do Ibura FLONAI, nas coordenadas geográficas $10.8324^{\circ} \mathrm{S} ; 37.134^{\circ} \mathrm{W}$ e corresponde a $7,65 \mathrm{ha}$ (Figura 1). A FLONAI é uma Unidade de Conservação de Uso Sustentável que tem no total 144 ha, entre os municípios de Nossa Senhora do Socorro e Laranjeiras, na Sub-Bacia Hidrográfica do Rio Cotinguiba, que é um tributário da Bacia Hidrográfica do Rio Sergipe.

A criação dessa Unidade de conservação teve por objetivo promover o uso múltiplo dos recursos florestais, a manutenção de um banco de germoplasma in situ de espécies florestais nativas, a manutenção e a proteção da biodiversidade, a recuperação de áreas degradadas e a pesquisa científica, conforme Decreto Federal de 19 de setembro de 2005 (BRASIL, 2005). 


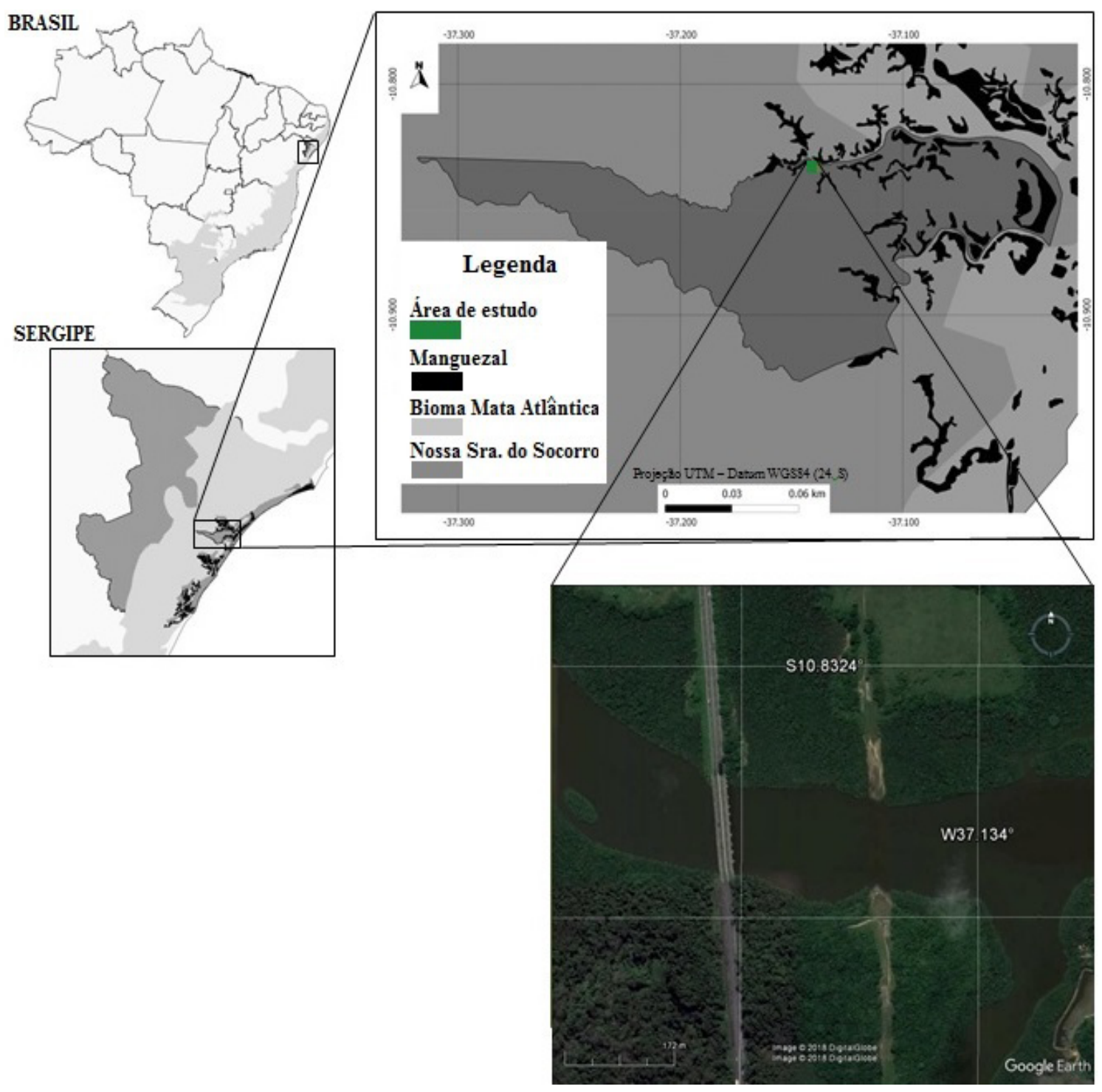

Figura 1. Mapa de localização da área de estudo, em um trecho de Manguezal, na Floresta Nacional do Ibura - FLONAI, na margem direita do Rio Cotinguiba no município de Nossa

Senhora do Socorro-SE. Imagem Google Earth (Satélite: Landsat/copernicus. Data da imagem 07/08/2017).

Sob o Domínio Fitogeográfico da Mata Atlântica, a paisagem da FLONAI e entorno é formada por várias unidades, tais como, fragmentos florestais, Manguezais e recursos hídricos, que correspondem a 37,37\%, e ainda, áreas antropizadas que representam e são predominantes na matriz da paisagem, totalizando $57,82 \%$ (VASCONCELOS e NERY, 2013).

O Patrimônio florístico da FLONAI foi estimado em um total de 328 espécies vegetais, das quais 324 são angiospermas, pertencentes a 82 famílias botânicas, três espécies são criptógamas (três famílias de samambaias) e uma espécie é gimnosperma. Dentre as famílias botânicas, 11 delas concentram a maior riqueza, com destaque para Fabaceae (30 gêneros e 50 espécies), seguida por Myrtaceae (sete gêneros e 20 
espécies) e Rubiaceae (11 gêneros e 15 espécies). Inclui-se também em seu patrimônio de biodiversidade, as espécies Laguncularia racemosa (L.) C. F. Gaertn. e Conocarpus erectus L. da família Combretaceae, espécies representantes típicas de manguezais (SANTANA et al. 2017).

Os solos compreendem os tipos Argissolos Vemelho Amarelo, Espodossolo, Chernossolo e os Gleissolos. A Geologia da região abrange sedimentos cenozóicos das Formações Superficiais Continentais e unidades mesozóicas da Bacia de Sergipe, apresentando em sua geomorfologia depósitos sedimentares costeiros com relevos dissecados em forma de colinas e interflúvios tabulares, com testemunhos da superfície tabular erosiva, além da ocorrência de áreas planas margeando próximo aos manguezais (SILVA et al. 2013b).

O clima predominante é Tropical Mesotérmico subúmido com temperaturas mensais variando entre $21,4^{\circ}$ e $25,2^{\circ} \mathrm{C}$ com precipitação média anual de $1.509 \mathrm{~mm}$ (SANTOS e ARAÚJO, 2013).

\section{Coleta e análise de dados}

Com auxílio de um aparelho de GPS foi georeferenciada uma área de 7,65 ha para a realização deste estudo, delimitando-se entre a borda e o final do Manguezal.

Foram traçados seis transectos perpendiculares à margem do rio, ao longo da borda com $600 \mathrm{~m}$ de extensão. Além disso, foi estabelecida uma distância de $80 \mathrm{~m}$ entre os transectos, abrangendo uma área da borda até o final do bosque.

Em cada transecto foram demarcadas parcelas de $10 \mathrm{~m}$ x $10 \mathrm{~m}$, distantes entre si em $50 \mathrm{~m}$. O número de parcelas variou de acordo com a largura do bosque, tendo sido lançadas 1, 2 ou 4 parcelas por transecto, totalizando treze parcelas (SCHAEFFERNOVELLI e CINTRÓN, 1986).

Para a caracterização do banco de plântulas mediu-se todos os indivíduos com altura de $0,30 \mathrm{~m}$ a 1,00 $\mathrm{m}$, em todas as parcelas instaladas. Também foram medidas plântulas da região considerada coroa (croa), localizada próxima ao meio do Rio Cotinguiba e do apicum, região considerada por alguns autores como de transição entre o Manguezal e o ambiente terrestre (terra firme). Foi instalada apenas uma parcela em cada uma dessas regiões e realizadas somente duas avaliações (fevereiro e junho).

As avaliações ocorreram nos meses de outubro de 2008 a junho de 2009, considerados períodos seco e chuvoso, respectivamente. Para as medições dos indivíduos, a altura total foi obtida com régua graduada e o diâmetro à altura do solo (DAS) foi obtido com paquímetro (0,05 mm).

Após realizar o georreferenciamento da área, gerou-se um mapa de localização em Software Quantum GIS 1.7.4, delimitando-a com imagem livre do Google Earth ${ }^{\circledR}$. Os dados obtidos foram processados e as análises realizadas por meio do Software Mata Nativa o2 (CIENTEC, 2005), licenciado para a Universidade Federal de Sergipe. 


\section{RESULTADOS E DISCUSSÃO}

Durante o período de levantamento do número de plântulas no bosque de mangue da FLONAI, foram identificadas três espécies típicas de mangue: Rhizophora mangle L., Laguncularia racemosa (L.) C. F. Gaertn. e Avicennia schaueriana Stapf \& Leechm. Ex Moldenke.

Verificou-se uma maior densidade de plântulas $\left(638\right.$ ind.ha $\left.{ }^{-1}\right)$ durante a primeira avaliação (período seco), reduzindo-se para $66 \%$ quando observado na segunda avaliação chegando a $27 \%$ na última avaliação comparando-se com o número de indivíduos encontrados na primeira avaliação, conforme observado na Tabela 1.

Tabela 1. Densidade de plântulas durante os períodos de avaliação em área de Manguezal da Flona do Ibura, na margem direita do Rio Cotinguiba, Nossa Senhora do Socorro-SE.

\begin{tabular}{|c|c|c|c|c|c|c|c|c|c|}
\hline Períodos & \multicolumn{3}{|c|}{ Outubro/20o8 } & \multicolumn{3}{|c|}{ Fevereiro/2009 } & \multicolumn{3}{|c|}{ Junho/2009 } \\
\hline Densidade & \multicolumn{3}{|c|}{638 ind.ha $^{-1}$} & \multicolumn{3}{|c|}{423 ind.ha-1 } & \multicolumn{3}{|c|}{238 ind.ha ${ }^{-1}$} \\
\hline \multirow{2}{*}{$\begin{array}{l}\text { Participação } \\
\text { por espécies }\end{array}$} & $\mathrm{Rh}$ & $\mathrm{Lg}$ & Avc & $\mathrm{Rh}$ & Lg & Avc & $\mathrm{Rh}$ & Lg & Avc \\
\hline & $92,8 \%$ & $1,2 \%$ & $6,0 \%$ & $96,4 \%$ & $0,0 \%$ & $3,6 \%$ & $96,8 \%$ & $0,0 \%$ & $3,2 \%$ \\
\hline
\end{tabular}

Em que Rh: R. mangle; Lg: L. racemosa; Avc: A. schaueriana.

Nota-se a espécie $R$. mangle com maior densidade de plântulas, contribuindo com mais de 90\% dos indivíduos em cada um dos três períodos avaliados, seguido da espécie A. schaueriana e apenas uma plântula encontrada de L. racemosa durante todo o período de avaliação.

O banco de plântulas encontrado corresponde a uma abundância reduzida ao longo de cada avaliação como pode ser verificado na Tabela 2.

Tabela 2. Abundância de plântulas encontradas em transectos, localizados no Manguezal da Flona do Ibura, na margem direita do Rio Cotinguiba, Nossa Senhora do Socorro-SE.

\begin{tabular}{llll}
\hline \multirow{2}{*}{ Espécies } & \multicolumn{1}{c}{ Outubro/2008 } & Fevereiro/2009 & Junho/2009 \\
\cline { 2 - 4 } & Abundância $\left(\mathrm{n}^{\mathrm{o}}\right)$ & & \\
\hline R. mangle & 77 & 53 & 30 \\
\hline L. racemosa & 1 & 0 & 0 \\
\hline A. schaueriana & 5 & 2 & 1 \\
\hline
\end{tabular}

Esta abundância de plântulas de $R$. mangle, pode estar relacionada com a capacidade dos indivíduos desta espécie em tolerarem um maior período de sombreamento, ocasionado pelo dossel do bosque. De modo contrário, este fator não favoreceu aos indivíduos de L. racemosa, uma vez que, de acordo com Jimenez et al. 
(1985), as copas fechadas inibem a sua regeneração de florestas, pois esta espécie é intolerante à sombra.

Em L. racemosa geralmente se observa uma elevada produção de propágulos e, consequentemente, uma elevada taxa de recrutamento e densidade de plântulas, conforme observado por Soares et al. (2008), em estudo realizado em mangue do complexo estuarino de Caravelas-BA.

Porém, nota-se que este padrão está concentrado em um período do ano, que é seguido por uma alta taxa de mortalidade. Isto ocorre, provavelmente, em função do esgotamento de reservas nutritivas e por competição com jovens e adultos, quando não há disponibilidade de espaço e luz, comprometendo o recrutamento de novos indivíduos. Isto foi observado durante a última avaliação do banco de plântulas, em junho de 2009.

Foi observada a ocorrência de dois indivíduos de $A$. schaueriana L., próximos às primeiras parcelas dos transectos um e seis. Foi verificado banco de plântulas sob o indivíduo próximo ao $\mathrm{T}_{6}$.

Para a altura, no bosque, o maior valor encontrado foi para uma única plântula de $L$. racemosa $(66,0 \mathrm{~cm})$, na primeira avaliação. Porém, esta plântula não foi mais encontrada posteriormente, pois possivelmente tenha sido levada pela força da maré, ou tenha morrido (Tabela 3).

Tabela 3. Altura média (cm) de plântulas em área de Manguezal da Flona do Ibura, na margem direita do Rio Cotinguiba, Nossa Senhora do Socorro-SE.

\begin{tabular}{|c|c|c|c|c|c|c|c|c|c|}
\hline \multirow{3}{*}{ Transectos } & \multicolumn{9}{|c|}{ Meses de avaliação (Altura média em cm) } \\
\hline & \multicolumn{3}{|c|}{ Outubro/2008 } & \multicolumn{3}{|c|}{ Fevereiro/2009 } & \multicolumn{3}{|c|}{ Junho/2009 } \\
\hline & $\mathrm{Rh}$ & $\mathrm{Lg}$ & Avc & $\mathrm{Rh}$ & Lg & Avc & $\mathrm{Rh}$ & $\operatorname{Lg}$ & Avc \\
\hline $\mathrm{T}_{1}$ & 45,84 & - & 40,17 & 59,28 & - & $45^{* * *}$ & 70,31 & - & $46,5^{* *}$ \\
\hline $\mathrm{T}_{2}$ & - & - & - & - & - & - & - & - & - \\
\hline $\mathrm{T}_{3}$ & * & * & * & 52,19 & - & - & 53,94 & - & - \\
\hline $\mathrm{T}_{4}$ & - & - & - & - & - & - & - & - & - \\
\hline $\mathrm{T}_{5}$ & 56,56 & - & $37,0^{* *}$ & 73,50 & - & - & 75,42 & - & - \\
\hline $\mathrm{T}_{6}$ & 49,42 & $66,0^{* *}$ & $31,0^{* *}$ & 63,59 & - & - & 73,14 & - & - \\
\hline
\end{tabular}

Em que Rh: R. mangle; Lg: L. racemosa; Avc: A. schaueriana. (*) Não houve avaliação. ( $\left.{ }^{* *}\right)$ Um indivíduo por espécie. $\left.{ }^{* * *}\right)$ Dois indivíduos por espécie.

Na parcela que a plântula de L. racemosa estava presente, verificou-se a existência de uma pequena clareira, o que provavelmente pode justificar a sua presença neste local, relacionada ao fator luminosidade. As plântulas de L. racemosa possuem menor tolerância a sombreamento (Jimenez et al. 1985), comparando-se com as outras espécies típicas de mangue. Possivelmente, esta afirmação pode ser 
considerada também para explicar o maior valor de diâmetro médio encontrado. Nas outras duas avaliações, os maiores valores de altura média foram de plântulas de $R$. mangle, seguido da $A$. schaueriana.

Considerando-se que no manguezal há um grande fluxo diário de água e matéria orgânica, em virtude da dinâmica das marés, a luz (intensidade luminosa) torna-se o fator de maior importância para o estabelecimento e desenvolvimento de plântulas, principalmente para aquelas que estão abaixo do dossel, no interior do bosque, comparando-se como as que habitam croas e/ou apicuns.

Em estudo da estrutura dos Manguezais em áreas em regeneração no Rio Pacoti no Ceará, foram registradas 400 plântulas $(<1,00 \mathrm{~m})$ em cinco espécies $(R$. mangle, A. germinans, A. schaueriana, L. racemosa e Conocarpus erectus L.) (Souza e Sampaio 2013). De acordo com os autores, L. racemosa apresentou-se mais adaptada a colonizar as áreas em regeneração e $R$. mangle predominou nas áreas pouco antropizadas (54\%), à medida que aumentou a densidade da cobertura de árvores, provavelmente por tolerância ao sombreamento. Por outro lado, a espécie $A$. germinans apresentou o menor número de indivíduos.

Já em área de Manguezal na Ilha de Cururu, no Maranhão, Pinheiro e Machado (2016) sugerem se tratar de um ambiente com perturbações continuadas, o que é reforçado pelo elevado número de indivíduos jovens (superior a 50\%), sendo $2,49 \%$ de plântulas (<1,oom), evidencia-se também estágio de regeneração se sobressaindo a espécies $R$. mangle.

O maior valor para diâmetro médio encontrado na primeira avaliação foi para única plântula de $L$. racemosa $(20,0 \mathrm{~mm})$. Em seguida, vieram os indivíduos de $R$. mangle e A. schaueriana. Já nas avaliações seguintes, as plântulas de $R$. mangle foram as que possuíram maiores diâmetros (Tabela 4).

Tabela 4. Diâmetro médio ( $\mathrm{mm}$ ) de plântulas em área de Manguezal da Flona do Ibura, na margem direita do Rio Cotinguiba, Nossa Senhora do Socorro-SE.

\begin{tabular}{lllllllllll}
\hline \multicolumn{1}{l}{ Meses de avaliação (Diâmetro em mm) } \\
\hline \multicolumn{7}{l}{ Outubro } & \multicolumn{7}{c}{ Fevereiro } & \multicolumn{1}{c}{ Junho } \\
\hline Transecto & Rh & Lg & Avc & Rh & Lg & Avc & Rh & Lg & Avc \\
\hline $\mathrm{T}_{1}$ & 14,27 & - & 5,0 & 15,87 & - & $6,85^{* * *}$ & 18,63 & - & $8,0^{* *}$ \\
$\mathrm{~T}_{2}$ & - & - & - & - & - & - & - & - & - \\
$\mathrm{T}_{3}$ & $*$ & $*$ & $*$ & 14,04 & - & - & 14,72 & - & - \\
$\mathrm{T}_{4}$ & - & - & - & - & - & - & - & - & - \\
$\mathrm{T}_{5}$ & 15,75 & - & $5,0^{* *}$ & 18,28 & - & - & 19,99 & - & - \\
$\mathrm{T}_{6}$ & 14,26 & $20,0^{* *}$ & $5,0^{* *}$ & 16,18 & - & - & 17,66 & - & - \\
\hline
\end{tabular}

Em que Rh: R. mangle; Lg: L. racemosa; Avc: A. schaueriana. ( $\left.{ }^{*}\right)$ Não houve avaliação. ${ }^{(*}$ ) Um indivíduo por espécie. $\left.{ }^{* * *}\right)$ Dois indivíduos por espécie. 
Por outro lado, a ocorrência de plântulas de $A$. schaueriana e L. racemosa observada com um padrão de tamanho de altura e diâmetro menores, pode estar relacionada, possivelmente, a baixa qualidade fisiológica dos propágulos, uma vez que para essas espécies, a presença de propágulos de maior peso e tamanho, tendem a formar plântulas mais vigorosas, conforme constatado por Silva e Maia (2018), avaliando o tamanho e o peso de propágulos de espécies de mangue na formação de plântulas no município de Acaraú-CE.

Na coroa (croa), localizada mais próxima ao meio do curso do rio, foram encontradas trinta e nove plântulas de L. racemosa na primeira avaliação (mês de fevereiro) e apenas quatorze, na avaliação realizada no mês de junho (Tabela 5).

Tabela 5. Abundância, altura média $(\mathrm{cm})$ e diâmetro médio $(\mathrm{mm})$ de plântulas da croa em área de Manguezal da Flona do Ibura, margem direita do Rio Cotinguiba, Nossa Senhora do Socorro- SE.

\begin{tabular}{lllllll}
\hline \multirow{2}{*}{ Parâmetros } & \multicolumn{5}{l}{ Meses de avaliação na Croa } \\
\cline { 2 - 7 } & \multicolumn{2}{l}{ Fevereiro/2009 } & & Junho/2009 & \\
\cline { 2 - 7 } & Rh. & Lg. & Avc. & Rh. & Lg. & Avc. \\
\hline Abundância & o & 39 & o & o & 14 & o \\
Altura média & o & 45,68 & o & o & 42,93 & o \\
Diâmetro médio & o & 8,16 & o & o & 7,96 & o \\
\hline
\end{tabular}

Em que Rh: R. mangle; Lg: L. racemosa; Avc: A. schaueriana.

A abundância dos indivíduos de L. racemosa, trinta e nove em apenas uma parcela localizada na coroa (contrariamente ao que foi encontrado dentro do bosque, apenas uma, que logo desapareceu ou morreu), pode ser explicada pela migração dos propágulos de dentro do bosque para esta área, uma vez que a coroa fica a poucos metros da borda. Pode-se também associar o resultado encontrado à teoria do tamanho e peso do propágulo, mencionado por Rabinowitz (1978), uma vez que estes podem ser carregados facilmente pelas marés.

Observou-se também uma grande quantidade de propágulos maduros, principalmente nos meses de março e abril, e outros emitindo radícula. Um fator de grande importância para esta abundância e desenvolvimento é a luminosidade a que estas plântulas estão expostas.

A redução ocorrida nesta parcela de trinta e nove indivíduos para quatorze pode estar associada à força da maré, arrancando as plântulas do solo inconsolidado e constantemente inundando. Com a redução do número de indivíduos, houve, consequentemente, uma redução nos valores da altura média e do diâmetro médio das plântulas pertencentes à esta parcela.

No apicum, verificou-se um grande número de indivíduos $(\mathrm{n}=74)$ em uma mesma parcela, na primeira avaliação, e oitenta e cinco na segunda. Este fato não é 
comum, pois este ambiente possui grande salinidade em virtude da menor influência de aporte de água e uma rápida evaporação quando esta área é banhada. Isto pode também ser explicado pela teoria do tamanho e peso dos propágulos, pois por serem menores e mais leves, os propágulos de L. racemosa são carregados facilmente para o interior do bosque (Rabinowitz, 1978), neste caso o apicum.

Apesar do alto número de plântulas encontradas, observou-se também a presença de várias plântulas mortas, com altura variando de $10 \mathrm{~cm}$ a $15 \mathrm{~cm}$, principalmente na primeira avaliação, onde a estação era considerada mais seca. Outro fato relevante, foi a presença de grãos (partículas) de sal nas folhas de indivíduos vivos e mortos (em decomposição), assim como na base do caule (solo). Este fato é considerado normal, pois uma das adaptações de algumas espécies típicas de mangue, no caso da $L$. racemosa, é a existência de glândulas excretoras de sal.

Em áreas de Manguezais em regeneração, no Rio Pacoti no Ceará, Souza e Sampaio (2013), observaram que a espécie L. racemosa predominou em área de regeneração (61\%), seguida de $A$. schaueriana (39\%). Para os autores, ainda que $A$. schaueriana não tenha tolerado o sombreamento, foi favorecida quanto ao alto teor de salinidade e fluxo não contínuo de água.

O Manguezal, por apresentar alta salinidade da água e do solo, níveis baixos de oxigênio no solo e ser frequentemente inundado pela maré, é considerado um ambiente que oferece condições hostis à maioria das plantas, sendo necessário que esses vegetais possuam adaptações especiais para sobreviver nestas áreas. As adaptações podem ser modificações morfológicas, anatômicas ou fisiológicas das espécies, em resposta a certas condições ambientais que se desenvolvem (Nascimento 2008).

A estratégia da $R$. mangle é a existência de membranas permeáveis à água e sais essenciais para as árvores em seu sistema de raízes, enquanto não permite a entrada de sais. Já as espécies de Avicennia permitem a entrada de sais, que saem através dos estômatos das folhas durante a transpiração, cristalizando-se na superfície foliar (Nascimento, 2008). Assim como Avicennia L., a L. racemosa possui glândulas excretoras (Olmos e Silva, 2003).

Considerando-se a estrutura morfológica das espécies típicas de mangue, as plântulas de L. racemosa da croa, aparentemente apresentavam-se mais jovens que as do apicum, ou seja, as plântulas do apicum possuíam aspecto de mais velhas e menos desenvolvidas. Possivelmente, este aspecto seja uma resposta à maior salinidade e menor aporte de água nesta região, porém estas obtiveram valores superiores quando comparadas às plântulas da croa. Pode-se considerar que estas plântulas sejam mais velhas que aquelas encontradas na croa, já que algumas do apicum possuíam flores.

Assim como na croa, no apicum foram encontrados apenas plântulas de $L$. racemosa. Nestas duas regiões houve uma redução do diâmetro médio e altura média na segunda avaliação. Apesar do aumento do número de indivíduos no apicum de setenta e quatro para oitenta e cinco, houve essa redução, pois certamente saíram indivíduos com valores maiores que o do critério de inclusão ( $\geq 30 \mathrm{~cm} \leq 1 \mathrm{~m}$ de altura) 
e entraram na avaliação indivíduos com valores menores do que aqueles que saíram, havendo este decréscimo nos parâmetros avaliados (Tabela 6).

Tabela 6. Abundância, altura média $(\mathrm{cm})$ e diâmetro médio $(\mathrm{mm})$ de plântulas no Apicum em área de Manguezal da Flona do Ibura, margem direita do Rio Cotinguiba, Nossa

Senhora do Socorro-SE.

\begin{tabular}{lllllll}
\hline \multirow{2}{*}{ Parâmetros } & \multicolumn{7}{l}{ Meses de avaliação no Apicum } \\
\cline { 2 - 7 } & \multicolumn{7}{l}{ Fevereiro } & Junho & \\
\cline { 2 - 7 } & Rh. & Lg. & Avc. & Rh. & Lg. & Avc. \\
\hline Abundância & $\mathrm{o}$ & 74 & $\mathrm{o}$ & $\mathrm{o}$ & 85 & $\mathrm{o}$ \\
Altura média & $\mathrm{o}$ & 51,94 & $\mathrm{o}$ & $\mathrm{o}$ & 55,09 & $\mathrm{o}$ \\
Diâmetro médio & $\mathrm{o}$ & 12,16 & $\mathrm{o}$ & $\mathrm{o}$ & 12,10 & $\mathrm{o}$ \\
\hline
\end{tabular}

Em que Rh: R. mangle; Lg: L. racemosa; Avc: A. schaueriana.

Análises da composição, qualidade e salinidade do solo e da água, devem ser realizadas, para então inferir-se mais sobre as possíveis causas e/ou tensores que atuam sobre o estabelecimento e posterior desenvolvimento de plântulas de mangue nesta área.

\section{CONCLUSÃO}

Em análise da regeneração de uma área de Manguezal da Flona Ibura, situada no Rio Cotinguiba, no estado de Sergipe, observou-se que banco de plântulas é composto por três espécies típicas de Manguezal: Rhizophora mangle, Laguncularia racemosa e Avicennia schaueriana. Porém, este banco encontra-se predominantemente povoado por indivíduos de Rhizophora mangle, cuja predominância pode estar associada à maior tolerância desta espécie ao sombreamento.

\section{REFERENCIAS}

CARVALHO MES, FONTES AL. 2007. A carcinicultura no espaço litorâneo Sergipano. Revista da Fapese, 3(1): 87-112.

CASASCO BS, SANTOS CLD, MARTA E. 2014. Recuperação de manguezais brasileiros. Revista Ceciliana, 6(1): 1-5. 
CIENTEC. 2005. Sistema para análise fitossociológica e elaboração de inventários e planos de manejo de florestas nativas. Mata Nativa 2: Versão 2.03.

ESPÍNDOLA MBD, ALMEIDA SL. 2015. A degradação dos mangues com foco no município de palhoça, com ênfase no manguezal da barra do Aririú. Revista Maiêutica, 3(1): 7-16.

GUIMARÃES HDB; BRAGA RAP, OLIVEIRA TH. 2012. Evolução da condição ambiental em fragmentos de mata atlântica na região metropolitana do Recife-PE. Revista Brasileira de Ciências Agrárias, 7(2): 306-314. DOI: https://doi.org/10.5039/agraria. v7iza1439

JIMENEZ JA, LUGO AE, CINTRÓN G. 1985. Tree mortality in mangrove forests. Biotropica, 17: 177-185. DOI: https://doi.org/10.2307/2388214

MEIRELES AJDA, CAMPOS AA. 2010. Componentes geomorfológicos, funções e serviços ambientais de complexos estuarinos no nordeste do Brasil. Revista da ANPEGE, 6(6): 9-107. DOI: https://doi.org/10.5418/RA2010.06o6.00o7

MELO JGDS, SILVA ERAC. 2018. Avaliação do estuário do Capibaribe (Recife/ Pernambuco, Brasil) acerca da degradação ambiental nos manguezais em ambientes urbanos. Revista Brasileira de Meio Ambiente, 1(1): 39-47.

MOURA-FÉ MMD, ALBUQUERQUE AGBM, FREITAS EMDN. 2014. A proteção do ecossistema manguezal pela legislação dos estados do Nordeste brasileiro. Estudos Geográficos, 12(2): 30-44.

NASCIMENTO ERD, SANTOSJL, GOUVEIASF. 2016. Configuraçãodosremanescentes florestais em uma área da Mata Atlântica do nordeste do Brasil: orientando medidas de conservação em escala municipal. Scientia Plena, 12(8): 1-10. DOI: https://doi. org/10.14808/sci.plena.2016.081001

NASCIMENTO MDSVD, SASSI, R. 2001. Interferências humanas na área de influência direta do Manguezal dos rios Timonha/Ubatuba, Estado do Piauí, Brasil. Revista Nordestina de Biologia, 15(1): 73-90.

NASCIMENTO SA. 2008. Ecofisiologia do manguezal. v. 1. Aracaju: Governo, 72 p.

OLMOS F, SILVA RS. 2003. Guará: ambiente flora e fauna dos Manguezais de SantosCubatão-Brasil. São Paulo: Empresa das Artes, 216p. 
PAULA ALDS, LIMA BKDS, MAIA RC. 2016. Production of Laguncularia racemosa (L.) C.F. Gaertn. (Combretaceae) and Avicennia sp. Stapf ex Ridl (Acanthaceae) seedlings. Revista Árvore, 40(3):377-385. DOI: https://doi.org/10.1590/o10o-67622016000300001

PINHEIRO CUB, MACHADO DDS. 2016. A Paisagem e a vegetação na Ilha de Curupu, Litoral Ocidental do Estado do Maranhão. Revista Ibero-Americana de Ciências Ambientais, 7(2): 84-10o. DOI: https://doi.org/10.60o8/SPC2179-6858.2016.002.0007

RABINOWITZ, D. 1978. Dispersal properties of mangrove propagules. Biotropica 10: 47-57. DOI: https://doi.org/10.2307/2388105

SANTANA JP, ROCHA PAD, SILVA TRD, RIBEIRO ASD, PRATA APDN. 2017. Floristic characterization of Ibura national forest, Sergipe, Brazil. Bioscience Journal, 33(2): 447-474. DOI: https://doi.org/10.14393/BJ-v33n2-33836

SANTOS JM, SANTOS LOD, COSTA JAS, MENEZES LCSD, HOLANDA FSR, BELLIN IC. 2015. Caracterização geoquímica orgânica e inorgânica de sedimentos de manguezais do Estuário São Francisco, Sergipe. Revista Virtual de Química, 7(6): 2139-2153. DOI: https://doi.org/10.5935/1984-6835.20150126

SANTOS WAD, ARAÚJO HMD. 2013. Clima e condições meteorológicas da sub-bacia hidrográfica do rio Cotinguiba-SE. Revista Boletim de Geografia, 31(1): 41-52. DOI: https://doi.org/10.4025/bolgeogr.v31i1.17110

SCHAEFFER-NOVELLI Y, CINTRÓN G. 1986. Guia para estudo deáreas de manguezal: estrutura, função e flora. São Paulo: Caribbean Ecological Research, 150 p.

SILVA MDSFD, MELO R. 2013a. Ecodinâmica na análise da fragilidade ambiental da Floresta Nacional do Ibura e seu entorno em nossa Senhora do Socorro, Sergipe. Revista GeoNordeste, Edição Especial, 2:137-157.

SILVA MDSFD, SILVA EGD, MELO R. 2013b. Uso e cobertura do solo da Floresta Nacional do Ibura e seu entorno, em Nossa Senhora do Socorro e Laranjeiras-SE. Revista Geografar, 8(2): 83-103. DOI: http://dx.doi.org/10.5380/geografar.v8i2.28965

SILVA MDSFD, SOUZA MES. 2014. Padrões espaciais de fragmentação florestal na FLONA do Ibura-Sergipe. Mercator, 13(3): 121-137. DOI: https://doi.org/10.4215/ RM2014.1303.0009.

SILVA NRD, MAIA RC. 2018. Avaliação do tamanho e peso de propágulos das espécies pioneiras de mangue na formação de plântulas para a recuperação de manguezais. Gaia Scientia, 12(3): 117-128. DOI: 10.22478/ufpb.1981-1268.2018v12n3.39306 
SOARES MLG, CHAVES FO, CAVALCANTI VF, PORTUGAL AMM, BARBOSA B. 2008. Caracterização das florestas de mangue do complexo estuarino de Caravelas (Bahia-Brasil). Boletim Técnico Cientifico, Tamandaré-PE, 16(5): 23-41.

SOUZA MMDA, SAMPAIO EVDSB. 2013. Estrutura dos mangues em áreas pouco antropizadas e em regeneração no Rio Pacoti-CE. Cadernos de Cultura e Ciência, 12(2):32-43.

VASCONCELOS CA, NERY MDPDA. 2013. Potencial ediversidade biológica da Floresta Nacional do Ibura, em Sergipe. Revista Ambivalências, 1(2): 129-144. DOI: https://doi. org/10.21665/2318-3888.v1n2p129-144 